\title{
Relationship between chlorine consumption and chlorination by-products formation for model compounds
}

\author{
E.E. Chang ${ }^{\mathrm{a}, *}$, P.C. Chiang ${ }^{\mathrm{b}}$, S.H. Chao ${ }^{\mathrm{a}}$, Y.L. Lin ${ }^{\mathrm{b}}$ \\ a Department of Biochemistry, Taipei Medical University, $250 \mathrm{Wu}$-Shin Street, Taipei 110, Taiwan \\ ${ }^{\mathrm{b}}$ Graduate institute of Environmental Engineering, National Taiwan University, 71 Chou-Shan Road, Taipei 106, Taiwan
}

Received 10 May 2005; received in revised form 10 November 2005; accepted 10 November 2005

Available online 10 January 2006

\begin{abstract}
The objective of this research is to investigate the relationship between chlorine decay and the formations of disinfection by-products (DBP), including trichloromethane (TCM) and chloroacetic acid (CAA) in the presence of four model compounds, i.e., resorcinol, phloroglucinol, $p$-hydroxybenzoic acid, and $m$-hydroxybenzoic acid. The chlorine degradation in model compounds with $\mathrm{OH}$ and/or $\mathrm{COOH}$ functional groups were rapid after chlorination. The TCM yields of carboxylic group substituted compounds (3-hydroxybenzoic acid [3-HBA], 4-hydroxybenzoic acid [4-HBA]) were found to be lower than that of the $m$-dihydroxy substituted compounds. Phloroglucinol, with one more $\mathrm{OH}$ substitution group than resorcinol, tends to form significant amounts of CAA after chlorination. However, it was observed that with the $\mathrm{COOH}$ substitution of 3-HBA and 4-HBA tend to exhibit more CAA formation potential than resorcinol. The developed parallel second and first-order reaction model for chlorine demand has been successfully utilized for TCM, CAA and DBP formation modeling. A high correlation between CAA and TCM was observed for the model compounds.
\end{abstract}

(C) 2005 Elsevier Ltd. All rights reserved.

Keywords: Chlorine consumption; Resorcinol (R); Phloroglucinol (P); Hydroxybenzoic acid (HBA); Tichloromethane (TCM); Chloroacetic acids (CAA); Chlorine decay model

\section{Introduction}

After the humic fraction within nature organic matter (NOM) was identified as a major precursor for trihalomethanes (THM) formation (Rook, 1976), most researches have focused their research on the humic portion of the NOM for disinfection by-products (DBPs) formation. Marhaba and Van (2000) concluded that the hydrophilic acid fraction was the most reactive precursor to the THM formation; while the hydrophobic neutral fraction was related to the formation of HAA. Liang and Singer (2001) reported that hydrophilic carbon also plays an important role in DBP formation, especially for waters with low humic content. Recent studies indicate that all fractions of NOM

\footnotetext{
${ }^{*}$ Corresponding author. Tel./fax: +886227369236.

E-mail address: eechang@tmu.edu.tw (E.E. Chang).
}

contribute to the formation of DBP (Sinha, 1999; Chang et al., 2001; Gang et al., 2003). It appears that the properties of humic substances have molecular weights of several hundred or larger, with weakly acidic functional groups (such as carboxylic group), and phenolic group which cause different types and amounts of DBPs (Cook and Langford, 1998).

Several studies suggested that aliphatic carboxylic acids, hydroxybenzoic acids, phenols and pyrrole derivatives are reactive substrates of organic precursors for THMs formation (Norwood et al., 1980; Korshin et al., 1997). Rook (1976) postulated that the $m$-dihydroxy structure of resorcinol was the principal TCM precursor in aquatic humic materials and proposed a reaction mechanism. The reaction products, $\mathrm{CHCl}_{3}$ and $\mathrm{CCl}_{3} \mathrm{COOH}$, were identified from the chlorination of resorcinol (Norwood et al., 1980). Chlorination could undergo electrophilic attack either at the chlorine atom (with displacement of hydroxyl, 
leading to chlorination) or at the hydroxyl group (with loss of chlorine). For example, $p$-hydroxybenzoic acid reacted rapidly to generate a mixture which is side-chain cleavage products of substitution and decarboxylation (Larson and Rockwell, 1979). Boyce and Hornig (1983) confirmed that the conversion of 1,3-dihydroxyaromatic precursors to THMs occurs in two stages. Extensive incorporation of halogen by electrophilic substitution and addition processes is followed by a complex series of hydrolysis and decarboxylation steps, which lead to TCM via carbon-carbon bond cleavage about the $\mathrm{C}_{2}$ site of the aromatic ring.

In many research reports, mathematical models were suggested to predict THM formation of specific source water (Engerholm and Amy, 1983; Amy et al., 1987; Chang et al., 1996; Gang et al., 2002). Gang et al. (2002) constructed a mathematical model of chlorine decay to predict the THM formation. The authors (Gang et al., 2003) also indicated that the THM formation in fractionated NOM was a function of chlorine consumption. As the molecular weight of the fraction decreased, THM yield coefficients increased. Katz (1986) suggested that the total organic carbon (TOC) had a strong correlation with chlorine demand, particularly when turbidity was less than 20 NTU in the filtrate. The effect of chlorine demand on DBP formation is generally not well known because NOM is composed of many types of organics. Aromatics and humic substance strongly react with chlorine that could be responsible for the initial chlorine demand (Dotson and Helz, 1984).

Most organic matters contributing to major DBP precursors in source water of Taiwan are small compounds, with a molecular weight of less than $1 \mathrm{KDa}$ which was measured by the ultrafiltration membranes (Chang et al., 2001; Chiang et al., 2002) However, only limited research has been done on DBPs formation with different functional groups of small molecular aromatic compounds. The objectives of this research were to: (1) develop the appropriate chlorine decay and DBP formation models for the selected four model compounds; (2) investigate the formation potential of trichloromethane (TCM) and chloroacetic acids (CAA) for the four model compounds; (3) evaluate the relationship between $\mathrm{CAA} / \mathrm{TCM}$ and chlorine consumption with different functional groups of model compounds.

\section{Material and methods}

\subsection{Sample preparation}

Four model compounds with different functional groups of benzene i.e., carboxylic and phenolic groups were selected in this investigation to represent small molecular NOM. The four model compounds include phloroglucinol (1,3,5-trihroxybenzene), resorcinol (1,3-dihydroxybenzene), $m$-hydroxybenzoic acid (3-HBA), and $p$-hydroxybenzoic acid (4-HBA). The dissolved organic carbon (DOC) concentrations for model compounds, using de-ionized water (Milli-Q SP), were prepared and adjusted to approximately $3.0( \pm 0.2) \mathrm{mg} / \mathrm{l}$ as $\mathrm{C}$. The characteristics of the model compounds are listed in Table 1.

\subsection{Evaluation of Chlorine consumption}

A 7-day chlorine consumption study was performed using $28 \mathrm{mg} / 1$ chlorine dosage (as $\mathrm{Cl}_{2}$ ), about 9 times the DOC dosage, to determine the chlorine consumption, trichloromethane formation potential (TCMFP), and chloroacetic acid formation potential (CAAFP). Throughout these chlorination experiments, all samples were chlorinated by $13 \%$ free chlorine (sodium hypochlorite) stock solution and added phosphate buffer $(\mathrm{pH}$ 7.0). A blank sample was prepared using the same amount of deionized ultra filtered water, and chlorinated under the same conditions as the other samples. Samples were chlorinated in 6 liter glass bottles and then carefully transferred into 150 amber glass bottles with Teflon-lined caps. A separate bottle containing the four model compounds samples was used for each reaction kinetic test. There were 12 experimental data for 3-HBA, 4-HBA, resorcinol and phloroglucinol,

Table 1

Physical/chemical properties of model compounds

\begin{tabular}{|c|c|c|c|c|}
\hline Model compound & Phloroglucinol & Resorcinol & 3-HBA & 4-HBA \\
\hline Molecular formula & $\mathrm{C}_{6} \mathrm{H}_{6} \mathrm{O}_{3}$ & $\mathrm{C}_{6} \mathrm{H}_{6} \mathrm{O}_{2}$ & $\mathrm{C}_{7} \mathrm{H}_{6} \mathrm{O}_{3}$ & $\mathrm{C}_{7} \mathrm{H}_{6} \mathrm{O}_{3}$ \\
\hline Molecular weight & 126.11 & 110.11 & 138.12 & 138.12 \\
\hline \multirow[t]{3}{*}{ Dissociation constant $\left(\mathrm{p} K_{\mathrm{a}}\right)$} & $\mathrm{p} K_{1} 8.0$ & $\mathrm{p} K_{1} 9.30$ & $\mathrm{p} K_{1} 4.06$ & $\mathrm{p} K_{1} 4.48$ \\
\hline & $\mathrm{p} K_{2} 9.2$ & $\mathrm{p} K_{2} 11.06$ & $\mathrm{p} K_{2} 9.92$ & $\mathrm{p} K_{2} 9.32$ \\
\hline & $\mathrm{p} K_{3} 14$ & & & \\
\hline Solubility in water & $10 \mathrm{~g} / 1\left(20^{\circ} \mathrm{C}\right)$ & $1000 \mathrm{~g} / 1\left(20^{\circ} \mathrm{C}\right)$ & slightly soluble $\left(20^{\circ} \mathrm{C}\right)$ & $5000 \mathrm{mg} / 1\left(25^{\circ} \mathrm{C}\right)$ \\
\hline & $\mathrm{OH}$ & & $\mathrm{COOH}$ & \\
\hline \multicolumn{5}{|l|}{ Structure } \\
\hline & & & & \\
\hline $\operatorname{SUVA}_{254}\left(1 \mathrm{mg}^{-1}\right)$ & 0.67 & 0.47 & 0.73 & 11.8 \\
\hline Produced company & Across & Across & Across & Merck \\
\hline
\end{tabular}


respectively, obtained at the specific time intervals, i.e., $0.08,0.17,0.33,0.50,0.67,0.83,1,3,6,24,48$ and $168 \mathrm{~h}$ during the reaction kinetic tests. The samples were kept headspace free in the dark at room temperature $\left(25 \pm 2{ }^{\circ} \mathrm{C}\right)$ until they were analyzed. Chlorine residual, DOC and UV adsorption were measured at different times for each bottle.

\subsection{Analytical methods}

Chlorine concentration was measured by $N, N$-diethyl- $p$ phenylenediamine (DPD) titration methods. DOC (TOC), $\mathrm{UV}_{254}, \mathrm{pH}$, and DBPFP analyses were conducted for each water sample. All analyses, unless otherwise noted, were performed according to the 19th edition of the Standards Methods (APHA, 1998). Water samples for DOC and UV analyses were conducted first by filtering through a prewashed $0.45 \mu \mathrm{m}$ filter, and then the sample was analyzed by a TOC instrument (O.I. Corporation model 700) and UV spectroscopy (Hitachi U-2000). TCM and CAA (including mono-, di-, and tri-chloroacetic acids) were analyzed by HP 6890GC/ECD according to Standard Methods 6230D and USEPA methods 552.2, respectively. Duplicate analyses were performed on each sample, and the average was reported. If the difference between the two values was greater than $15 \%$, a third analysis was performed, and the average of all three values was reported.

\subsection{Models of chlorine decay and DBP formation}

Owing to the unique characterization of the selected target compounds, many models developed in the literature (Gang et al., 2002, 2003) can not fit the experimental data well. As a result, the parallel first-order reaction model, which was originally derived by Gang et al. (2002) could be modified as the following:

$$
\begin{aligned}
& \mathrm{NOM}_{\mathrm{R}}+\mathrm{Cl}_{2} \stackrel{k_{\mathrm{R}}}{\rightarrow} R-X \text { (rapid) } \\
& \frac{\mathrm{d} C_{\mathrm{R}}}{\mathrm{d} t}=-k_{\mathrm{R}} C^{n} \\
& \mathrm{NOM}_{\mathrm{S}}+\mathrm{Cl}_{2} \stackrel{k_{\mathrm{S}}}{\rightarrow} R-X \text { (slow) } \\
& \frac{\mathrm{d} C_{\mathrm{S}}}{\mathrm{d} t}=-k_{\mathrm{S}} C
\end{aligned}
$$

in which $C_{\mathrm{R}}$ is the chlorine concentration participating in a hypothetical separate rapid reaction; $C_{\mathrm{S}}$ is the chlorine concentration participating in a hypothetical separate slow reaction; $R$ and $X$ are chlorinated by-products; $n$ and $m$ are the order of the reaction with respect to the rapid and slow reactions, respectively.

The value of $n$ and $m$ are determined by the best fit as compared with the suggested reaction orders. Integrating these rate equations (Eqs. (2) and (4)) with $C_{\mathrm{R} 0}=f C_{0}$ and $C_{\mathrm{S} 0}=(1-f) C_{0}$, the chlorine concentration at any time is

$$
\begin{aligned}
C(t)= & {\left[-K_{\mathrm{R}} \cdot t \cdot(-n+1)+f \cdot C_{0}^{-n+1}\right]^{\frac{1}{-n+1}} } \\
& +\left[-K_{\mathrm{S}} \cdot t \cdot(-m+1)+f \cdot C_{0}^{-m+1}\right]^{\frac{1}{-m+1}} \quad(n, m \neq 1) \\
C(t)= & C_{0} \cdot\left\{f \cdot e^{-K_{\mathrm{R}} \cdot t}+(1-f) \cdot e^{-K_{\mathrm{S}} \cdot t}\right\} \quad(n, m=1)
\end{aligned}
$$

in which $C(t)$ is the chlorine concentration at any time $t$ $(\mathrm{mg} / \mathrm{l}), C_{0}$ is the initial chlorine concentration (dose), $f$ is the fraction of the chlorine demand attributed to rapid reactions, $k_{\mathrm{R}}$ is the rate constant for rapid reactions, and $k_{\mathrm{S}}$ is the rate constant for slow reactions.

The coefficients $\left(f, K_{\mathrm{R}}\right.$, and $\left.K_{\mathrm{S}}\right)$ obtained from the chlorine decay model (Eq. (5) or Eq. (6)) were used to predict the TCM, CAA, and DBP (TCM + CAA) formations. Eqs. (7)-(9) assume that the TCM, CAA and DBP formations are a function of chlorine consumptions with respect to the rapid and slow reactions:

$\mathrm{TCM}=A\left(C_{\mathrm{R} 0}-C_{\mathrm{R}}\right)^{n}+B\left(C_{\mathrm{S} 0}-C_{\mathrm{S}}\right)^{m}$
$\mathrm{CAA}=C\left(C_{\mathrm{R} 0}-C_{\mathrm{R}}\right)^{n}+D\left(C_{\mathrm{S} 0}-C_{\mathrm{S}}\right)^{m}$
$\mathrm{DBP}=E\left(C_{\mathrm{R} 0}-C_{\mathrm{R}}\right)^{n}+F\left(C_{\mathrm{S} 0}-C_{\mathrm{S}}\right)^{m}$

in which $A$ and $B$ are the TCM yield coefficient from the rapid and slow chlorine consumed, respectively; $C$ and $D$ are the CAA yield coefficients from the rapid and slow chlorine consumed, respectively; $E$ and $F$ are the DBP yield coefficients from the rapid and slow chlorine consumed, respectively.

The parameters $n, m, f, k_{\mathrm{R}}, k s$ and yield coefficients $(A, B, C, D, E, F)$ were determined by non-linear regression software (SYSTAT 5.01).

\section{Results and discussion}

\subsection{Chlorine demand and decay modeling}

Fig. 1 shows the chlorine demand and residual chlorine associated with the hydroxybenzene and hydroxybenzoic acid during the chlorination process, respectively. It was observed that the chlorine consumption increased rapidly within the first $3 \mathrm{~h}$ and then gradually decayed after $3 \mathrm{~h}$

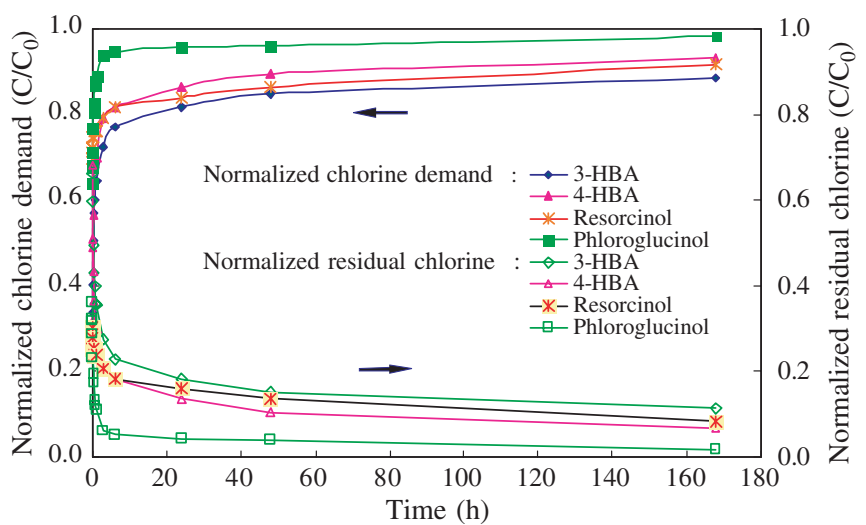

Fig. 1. Normalized chlorine demand and decay curves of model samples during the chlorination process. 
of chlorination. Since the phenolates (dissociated form of phenols) from model compounds were responsible for the fast reaction with chlorine, all water samples consumed over $80 \%$ of the initial chlorine dose within the first $3 \mathrm{~h}$, especially for the resorcinol, which had the highest chlorine consumption rate at $10 \mathrm{~min}$.

The parallel second and first-order reaction model for chlorine demand derived in this study is the best fit as compared with the parallel first-order model (derived by Gang et al., 2002), $n$-order chlorine decay model, parallel second order and parallel first order and second order. Table 2 presents the chlorine decay constants and fitting parameters for the model compounds. The chlorine data of hydroxybenzene and hydroxybenzoic acid in Fig. 2 fit the model well, yielding the correlation coefficients of $0.985-0.991$.

The constants of rapid decay rates $\left(K_{\mathrm{R}}=0.32\right.$ $\left.5.051 \mathrm{mg}^{-1} \mathrm{~h}^{-1}\right)$ in Table 2 were much higher than those of the slow decay rates $\left(k_{\mathrm{S}}=0.006-0.028 \mathrm{~h}^{-1}\right)$ for all model samples. The values of $k_{\mathrm{R}}$ for the hydroxybenzoic acids were much smaller than those of the hydroxybenzene samples. The proportion constants $(f)$ shown in Table 2 ranged from $76 \%$ to $91 \%$ of the chlorine consumption. Differences in the reaction kinetics observed between these four compounds may be separated into two groups. For resorcinol and phloroglucinol, the chlorine consumptions were higher at first and increased gradually afterwards; whereas for 3HBA and 4-HBA, chlorine consumptions were lower at first and increased rapidly afterwards.

Larson and Rockwell (1979) and Gallard and Gunten (2002) revealed that resorcinol, with two activating $-\mathrm{OH}$ groups, could release electrons rapidly, leading to the elec-

Table 2

Chlorine decay constants and fitting parameters of model compounds (chlorine dose $=28 \mathrm{mg} / \mathrm{l}$ )

\begin{tabular}{lllll}
\hline Compounds & $f$ & $K_{\mathrm{R}}\left(\mathrm{mg}^{-1} \mathrm{~h}^{-1}\right)$ & $K_{\mathrm{S}}\left(\mathrm{h}^{-1}\right)$ & $R^{2}$ \\
\hline 3-HBA & 0.760 & 0.319 & 0.006 & 0.995 \\
4-HBA & 0.819 & 0.328 & 0.008 & 0.998 \\
Resorcinol & 0.782 & 5.051 & 0.008 & 0.995 \\
Phloroglucinol & 0.913 & 1.225 & 0.028 & 0.985 \\
\hline
\end{tabular}

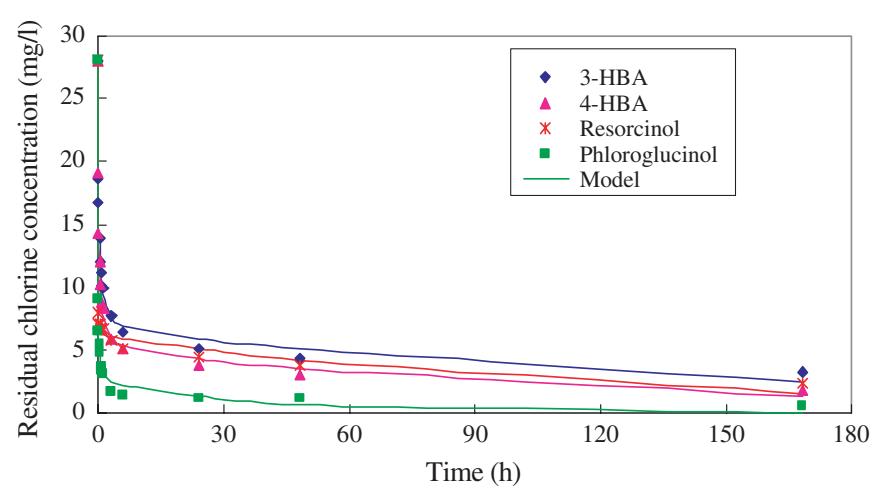

Fig. 2. The residual chlorine concentration and predictive data during the chlorination process. trophilic addition and substitution reactions while chlorination was proceeding. Boyce and Hornig (1983) also pointed out that when both $\mathrm{OH}$ groups on an aromatic ring are located at an appropriated orientation to stabilize the transition state of the reaction through the donation of electron density, an electrophilic substitution mechanism could easily occur. These observations suggest that the aromatic carbon site adjacent to the $\mathrm{C}_{1}$-hydroxyl group be inverted to electrophilic substitution by chlorine. However, phloroglucinol is highly symmetric and may form a resonance-stabilized intermediate because of three $-\mathrm{OH}$ groups. These three $-\mathrm{OH}$ groups may impede series of hydrolysis as well as decarboxylation with $\mathrm{C}-\mathrm{C}$ bond cleavage on the aromatic ring resulting in a lower $k_{\mathrm{R}}$ value of phloroglucinol $\left(1.2251 \mathrm{mg}^{-1} \mathrm{~h}^{-1}\right)$ than that of resorcinol $\left(5.0511 \mathrm{mg}^{-1} \mathrm{~h}^{-1}\right)$.

As for hydroxybenzoic acids with moderately deactivating substituents $(-\mathrm{COOH})$, the electron density on the benzene ring would be lowered during the ionization process of carboxyl group. The chlorination of carboxyl groups proceeds much slower than the chlorination of resorcinol and phloroglucinol, which is because that hydroxybenzoic acid reacts rapidly to give a decarboxylation product (Larson and Rockwell, 1979). As for the chlorine consumption rate between 3-HBA and 4-HBA, it was observed that there was a higher value for 4-HBA because the $p$-position of $\mathrm{OH}$ and $\mathrm{COOH}$ on the aromatic ring is more active than the $m$-position of $\mathrm{OH}$ and $\mathrm{COOH}$ which facilitates the chlorine reaction on hydroxybenzoic acid.

\subsection{TCM, CAA and DBP formation kinetics and modeling}

Since the chlorine decay model was determined as the parallel second order (rapid reaction) and first order (slow reaction), the chlorine decay model could be simplified as:

$C(t)=C_{0} \cdot\left[\frac{f}{f C_{0} k_{\mathrm{R}} t+1}+(1-f) e^{-k_{s} t}\right]$

With the above observations, the TCM, CAA and DBP formation models could also be simplified as

$$
\begin{aligned}
\mathrm{TCM}= & A\left\{f C_{0} \cdot\left[1-\frac{1}{f C_{0} k_{\mathrm{R}} t+1}\right]\right\}^{n} \\
& +B\left\{(1-f) C_{0}\left[1-e^{-k_{s} t}\right]\right\}^{m} \\
\mathrm{CAA}= & C\left\{f C_{0} \cdot\left[1-\frac{1}{f C_{0} k_{\mathrm{R}} t+1}\right]\right\}^{n} \\
& +D\left\{(1-f) C_{0}\left[1-e^{-k_{s} t}\right]\right\}^{m} \\
\mathrm{DBP}= & E\left\{f C_{0} \cdot\left[1-\frac{1}{f C_{0} k_{\mathrm{R}} t+1}\right]\right\}^{n} \\
& +F\left\{(1-f) C_{0}\left[1-e^{-k_{s} t}\right]\right\}^{m}
\end{aligned}
$$

The experimental data was inserted into the DBP formation model via Eqs. (11)-(13). Table 4 reveals correlation coefficients for TCM, CAA, and DBP formation model at different order of reaction. It was clearly observed that the parallel third and first order $(R(3,1))$ exhibits the 


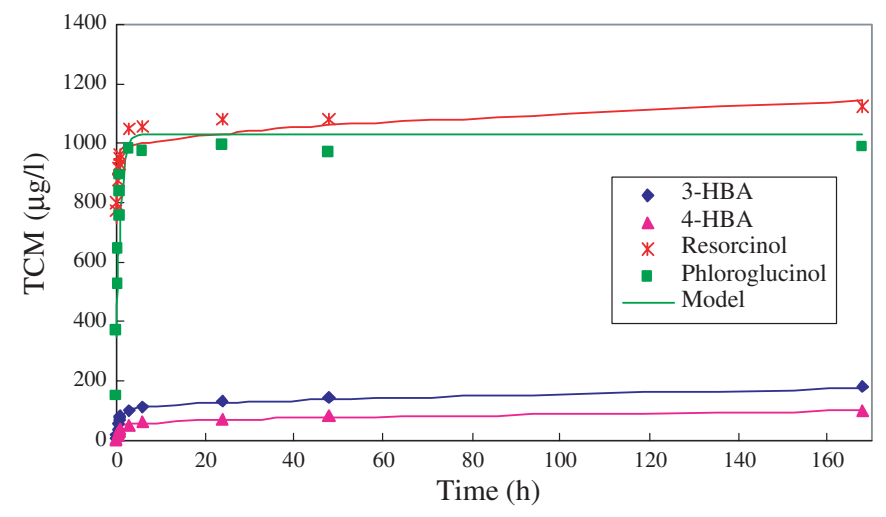

Fig. 3. The TCM formation and predictive data for model compounds during the chlorination process.

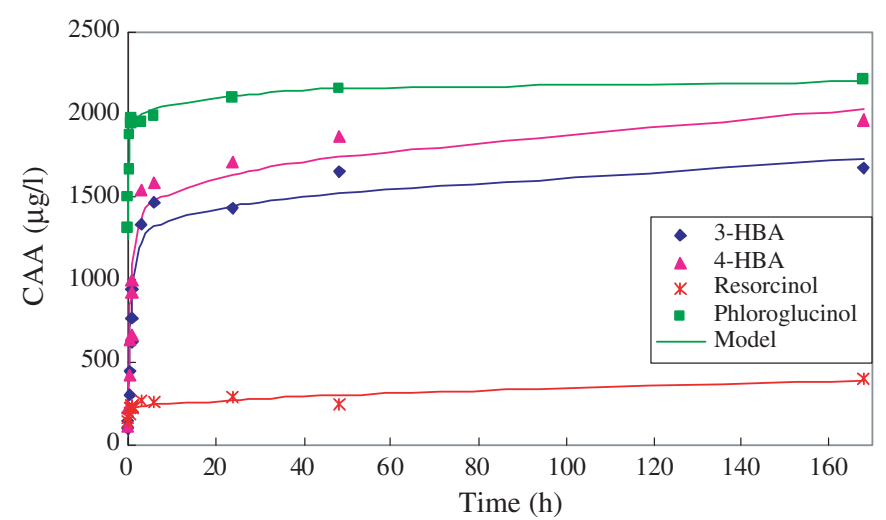

Fig. 4. The CAA formation and predictive data for model compounds during the chlorination process.

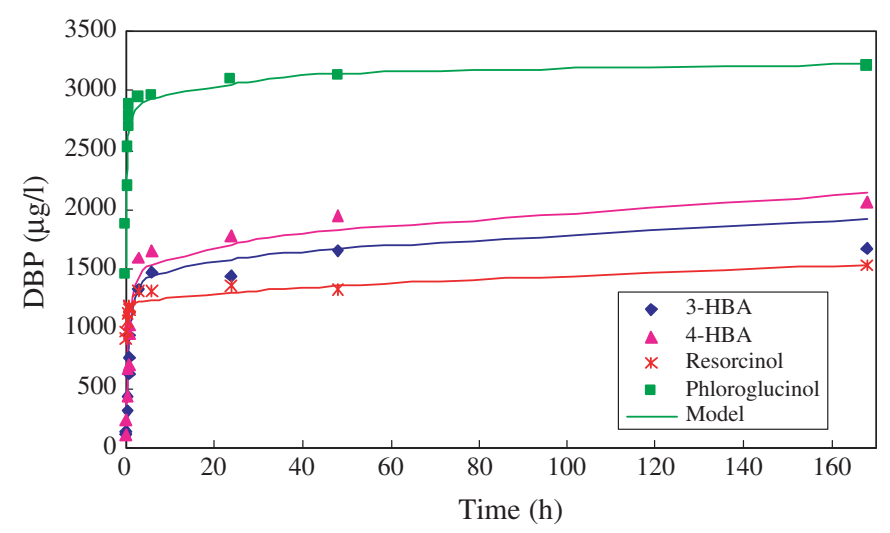

Fig. 5. The DBP formation and predictive data for model compounds during the chlorination process.

highest correlation coefficient (best fit) for the four model compounds with the exception of $\mathrm{P}$ for CAA model prediction. Figs. 3-5 show that the data fit the TCM, CAA and DBP formation model quite well, with correlation coefficients (0.854-0.996), which indicates that TCM, CAA and DBP formations were a function of chlorine consumption for the model compounds, which was consistent with other findings (Larson and Rockwell, 1979; Norwood et al., 1980; Boyce and Hornig, 1983).

The rate of $\mathrm{CHCl}_{3}$ production and chlorine consumption varied with each model compound, however, the overall data showed two distinct patterns. The first pattern is exhibited by the $m$-dihydroxy substituted compounds and reflects a generally rapid and simultaneous exertion of both chlorine demand and TCM production (Figs. 1 and 3). The data suggests that this carbon between two hydroxyl groups should be responsible for TCM production (Larson and Rockwell, 1979; Rook, 1976).

The second pattern is demonstrated by the hydroxybenzoic acids data and indicates that TCM is a minor reaction product. The hydroxybenzoic acids pattern produces approximately 5-10-fold less chloroform formation potential than $m$-hydroxy substituted compounds (Table 3), although the chlorine demand remains relatively high. This phenomenon may be explained by the loss of a doubly activated carbon between two free hydroxyls in 3-HBA and 4HBA.

Because of the hydroxy configuration, the molecule will probably undergo oxidative decarboxylation with substitution of chlorine in place of carboxyl (Larson and Rockwell, 1979), continuous chlorination and final cleavage could then occur at the chlorination site. The hydroxybenzoic acids pattern produces similar trichloromethane formation results. In addition to the chlorine demand for TCM production and oxidation, the evidence suggests that a portion of the chlorine demand is due to the incorporation of chlorine into non- $\mathrm{CHCl}_{3}$ reaction products.

The chloroacetic acids (summation of mono-, di-, and tri-chloroacetic acid) were analyzed from the chlorination of model compounds as the disinfection by-products. In phloroglucinol, CAA formation rates also were initially rapid, corresponding with the rapid consumption of chlorine, followed by a slower, declining rate of production (Fig. 4). Above 90\% CAA was generated within the first $3 \mathrm{~h}$, as compared with the CAA formed at the end of reaction time-7 days. Christman et al. (1978) have noted that chlorination of resorcinol at high $\mathrm{Cl}_{2}$ /substrate ratios enhance-the accumulation of chlorinated acids, including chlorobutenedioic acid, dichloroacetic acid, and trichloroacetic acid etc. More electrophilic - $\mathrm{OH}$ groups of phloroglucinol have lower $\mathrm{p} K_{\mathrm{a}}$ and higher $\mathrm{SUVA}_{254}$ (Table 1) which yields approximately 5-fold CAA and 2-fold DBP (TCM and CAA) formation potential than resorcinol (Table 3). Further, existing - $\mathrm{COOH}$ substitution substances have lower $\mathrm{p} K_{\mathrm{a}}$ values and generate more CAA as shown in Fig. 4. Therefore, the distribution of various species of chlorinated products also depends on the acidity $\left(\mathrm{p} K_{\mathrm{a}}\right), \mathrm{SUVA}_{254}$, and characteristics of the substrate in solution (Trussell and Umphres, 1978; Peters et al., 1980; Gallard and Gunten, 2002).

The TCM (CAA) yield coefficient is defined as the ratio between the concentration $(\mathrm{mg} / \mathrm{l})$ of TCM (CAA) formed and the concentration of chlorine consumed $(\mathrm{mg} / \mathrm{l})$. Table 5 presents the TCM, CAA and DBP yield coefficients for 
Table 3

TCM, CAA and DBP formation for model compounds treated by chlorine

\begin{tabular}{|c|c|c|c|c|}
\hline Model compound & 3-HBA & 4-HBA & Resorcinol & Phloroglucinol \\
\hline $\begin{array}{l}\text { Initial concentration } \\
(\mathrm{mg}-\mathrm{C} / \mathrm{l})\end{array}$ & 3.0 & 3.0 & 3.0 & 3.0 \\
\hline \multicolumn{5}{|c|}{ Specific chlorine demand ( $\left.m g \mathrm{Cl}_{2} / m g-C\right)$} \\
\hline $1 \mathrm{~h}$ & 6.0 & 6.5 & 7.1 & 8.3 \\
\hline $3 \mathrm{~h}$ & 6.8 & 7.4 & 7.4 & 8.8 \\
\hline $6 \mathrm{~h}$ & 7.2 & 7.6 & 7.6 & 8.8 \\
\hline $24 \mathrm{~h}$ & 7.6 & 8.1 & 7.8 & 8.9 \\
\hline $48 \mathrm{~h}$ & 7.9 & 8.3 & 8.1 & 9.0 \\
\hline $168 \mathrm{~h}$ & 8.3 & 8.7 & 8.6 & 9.2 \\
\hline \multicolumn{5}{|c|}{ Specific TCM ( $\mu g$ TCM/mg-C) } \\
\hline $1 \mathrm{~h}$ & 27 & 14 & 322 & 297 \\
\hline $3 \mathrm{~h}$ & 33 & 17 & 350 & 328 \\
\hline $6 \mathrm{~h}$ & 37 & 21 & 352 & 325 \\
\hline $24 \mathrm{~h}$ & 44 & 23 & 360 & 332 \\
\hline $48 \mathrm{~h}$ & 49 & 26 & 361 & 323 \\
\hline $168 \mathrm{~h}$ & 60 & 32 & 375 & 330 \\
\hline \multicolumn{5}{|c|}{ Specific CAA ( $\mu g$ CAA/mg-C) } \\
\hline $1 \mathrm{~h}$ & 316 & 333 & 78 & 660 \\
\hline $3 \mathrm{~h}$ & 445 & 514 & 87 & 652 \\
\hline $6 \mathrm{~h}$ & 488 & 529 & 86 & 663 \\
\hline $24 \mathrm{~h}$ & 479 & 570 & 96 & 700 \\
\hline $48 \mathrm{~h}$ & 552 & 623 & 81 & 717 \\
\hline $168 \mathrm{~h}$ & 560 & 655 & 134 & 738 \\
\hline \multicolumn{5}{|c|}{ Specific DBP ${ }^{\mathrm{a}}(\mu g D B P / m g-C)$} \\
\hline $1 \mathrm{~h}$ & 343 & 347 & 400 & 958 \\
\hline $3 \mathrm{~h}$ & 477 & 531 & 437 & 980 \\
\hline $6 \mathrm{~h}$ & 525 & 550 & 437 & 988 \\
\hline $24 \mathrm{~h}$ & 523 & 593 & 456 & 1032 \\
\hline $48 \mathrm{~h}$ & 601 & 649 & 442 & 1041 \\
\hline $168 \mathrm{~h}$ & 620 & 687 & 509 & 1068 \\
\hline
\end{tabular}

Chlorine dose $=28 \mathrm{mg} / \mathrm{l}$ as $\mathrm{Cl}_{2}$.

${ }^{\mathrm{a}} \mathrm{DBP}=\mathrm{TCM}+\mathrm{CAA}$.

Table 4

Correlation coefficients for TCM, CAA, and DBP formation models at different order of reaction

\begin{tabular}{|c|c|c|c|c|c|c|}
\hline \multirow[t]{2}{*}{$\overline{\mathrm{DBPs}}$} & \multirow[t]{2}{*}{ Organics } & \multicolumn{5}{|c|}{$R_{i}(n, m)^{\mathrm{a}}$} \\
\hline & & $R_{1}(1,1)$ & $R_{2}(1.5,1)$ & $R_{3}(2,1)$ & $R_{4}(3,1)$ & $R_{5}(2,2)$ \\
\hline \multirow[t]{4}{*}{$\mathrm{TCM}$} & 3-HBA & 0.885 & 0.947 & 0.994 & $0.996^{\mathrm{b}}$ & 0.948 \\
\hline & 4-HBA & 0.585 & 0.918 & 0.979 & 0.991 & 0.913 \\
\hline & $\mathrm{R}$ & 0.670 & 0.756 & 0.858 & 0.877 & 0.749 \\
\hline & $P$ & 0.556 & 0.658 & 0.808 & 0.860 & 0.714 \\
\hline \multirow[t]{4}{*}{ CAA } & 3-HBA & 0.724 & 0.817 & 0.927 & 0.958 & 0.858 \\
\hline & 4-HBA & 0.754 & 0.839 & 0.938 & 0.965 & 0.865 \\
\hline & $\mathrm{R}$ & 0.759 & 0.789 & 0.836 & 0.854 & 0.810 \\
\hline & $P$ & 0.924 & 0.963 & 0.759 & 0.559 & 0.907 \\
\hline \multirow[t]{4}{*}{ DBP } & 3-HBA & 0.739 & 0.831 & 0.936 & 0.965 & 0.868 \\
\hline & 4-HBA & 0.759 & 0.843 & 0.940 & 0.966 & 0.868 \\
\hline & $\mathrm{R}$ & 0.728 & 0.796 & 0.885 & 0.909 & 0.787 \\
\hline & $P$ & 0.790 & 0.902 & 0.997 & 0.959 & 0.954 \\
\hline
\end{tabular}

\footnotetext{
${ }^{\text {a }} R_{i}(n, m)$ denotes the selected type of reaction order in which the $n$ and $m$ represent the order for rapid and slow reactions, respectively.

b The numerical values in the 'block' denote the correlation coefficients with the best fit representing the reaction order utilizes for model prediction.
}

model compounds at different order of reaction. In Table 5, it was observed that there were two distinct patterns, i.e., hydroxybenzoic acid (3-HBA and 4-HBA) and hydroxyl benzene ( $\mathrm{R}$ and $\mathrm{P}$ ), exhibited their respective reaction order $(n, m)$ and DBP yield coefficient. Reckhow et al. (1990) also found that the specific DBP formation was related to the activated aromatic matter, whereas activated aromatic content was correlated with chlorine consumption. Gang et al. (2003) reported that there was no strong correlation between molecular weight and chlorine decay kinetics. With the above evidence, it suggests the amount of DBP generated be site-specific in practice, and the chlorine reacting mechanism be dependent on the nature of target compounds in principle. In this study, although these four small model compounds have their respective functional group reacted with chlorine to form DBP, the DBP formation is actually simulated by a chlorine demand model. The concept of DBP yield coefficient was useful for quantifying the difference in species production and evaluating the effect of organic precursor reduction.

\subsection{Relationship between TCM and CAA}

The specific chlorine demand (SCD) in Fig. 6 was defined as the ratio between the chlorine demand $(\mathrm{mg} / \mathrm{l})$ and the initial DOC concentration $(\mathrm{mg} / \mathrm{l})$ at the reaction times of 1,3 and $168 \mathrm{~h}$. In the first hour, the SCD and specific DBPFP (DBP formation potential/DOC concentration) of hydroxybenzenes are slightly higher than those of hydroxybenzoic acids, and the specific DBPFP of phloroglucinol was the highest among the four model compounds. However, no relationships between specific DBPFP and SCD of model compounds were observed based on the limited data collected at various times.

Fig. 7 shows the relationship between TCM and CAA formation potential of model compounds under different chlorination times (1, 3 and $168 \mathrm{~h})$. After linear regression of experimental data, a high correlation between CAA and TCM concentration was observed. However, there are two patterns of DBP correlation based on the slopes of linear curves in Fig. 7. The hydroxybenzoic acids pattern produces a higher slope $(>10)$ than that of the $m$-hydroxy substituted compounds (slope $<1$ ). These observations suggest that the aromatic carboxyl group has a strong correlation to the formation of CAA (Cook and Langford, 1998; Pomes et al., 1999). However, oxidative decarboxylation of dihydroxybenzoic acid was not observed which was consistent with the findings suggested by Norwood et al. (1980). Therefore, the formation of DBP is highly dependent on the nature of the organic matter.

\section{Conclusions}

This study shows that the four model compounds of small organic DBP precursors lead to high chlorine demand and high DBP formation potential. The chlorine degradation in model compounds with $\mathrm{OH}$ and/or $\mathrm{COOH}$ 
Table 5

TCM, CAA and DBP yield coefficients for model compounds expressed as the best fit (referred to Table 4)

\begin{tabular}{lllllrrrrr}
\hline Organics & $\mathrm{A}$ & $\mathrm{B}$ & $R^{2}$ & $\mathrm{C}$ & $\mathrm{D}$ & $R^{2}$ & $\mathrm{E}$ & $\mathrm{F}$ \\
\hline 3-HBA & 0.01 & 14.59 & 0.996 & 0.15 & 79.67 & 0.958 & 0.16 & 94.21 \\
4-HBA & 0.01 & 10.61 & 0.991 & 0.13 & 132.05 & 0.965 & 0.13 & 142.70 \\
R & 0.095 & 33.03 & 0.877 & 0.02 & 34.90 & 0.991 & 0.12 & 67.93 \\
P & 0.052 & 63.65 & 0.860 & 15.62 & 75.71 & 0.963 & 4.44 & 136.15 & 0.966 \\
\hline
\end{tabular}

A: the TCM yield coefficient from the rapid chlorine consumption, B: the TCM yield coefficient from the slow chlorine consumption, C: the CAA yield coefficient from the rapid chlorine consumption, D: the CAA yield coefficient from the slow chlorine consumption, E: the DBP yield coefficient from the rapid chlorine consumption, F: the DBP yield coefficient from the slow chlorine consumption.
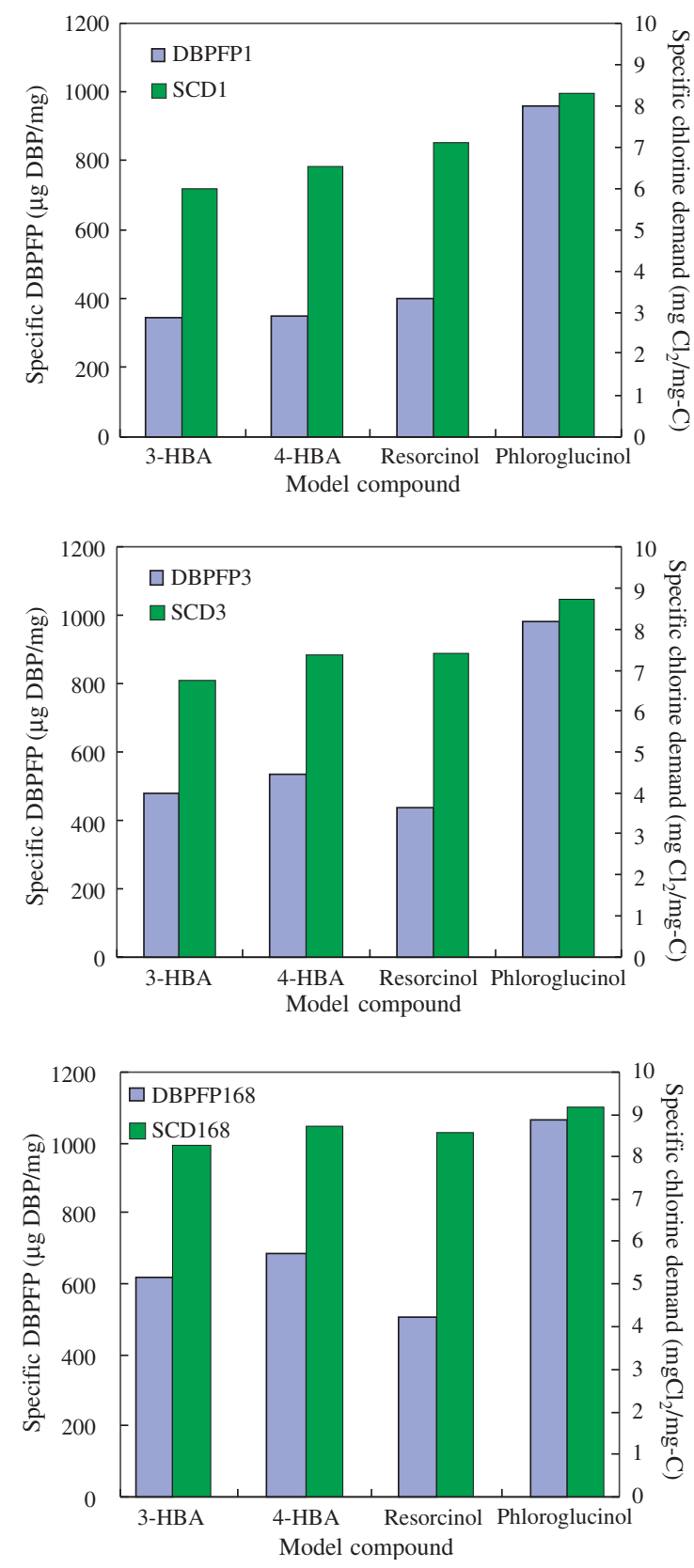

Fig. 6. Relationship between specific DBPFP and specific chlorine demand (SCD) for model compounds at reaction time of 1,3 and $168 \mathrm{~h}$, respectively.

functional groups were rapid after chlorination. It is noted that chlorination of model compounds at high $\mathrm{Cl}_{2} /$ sub-

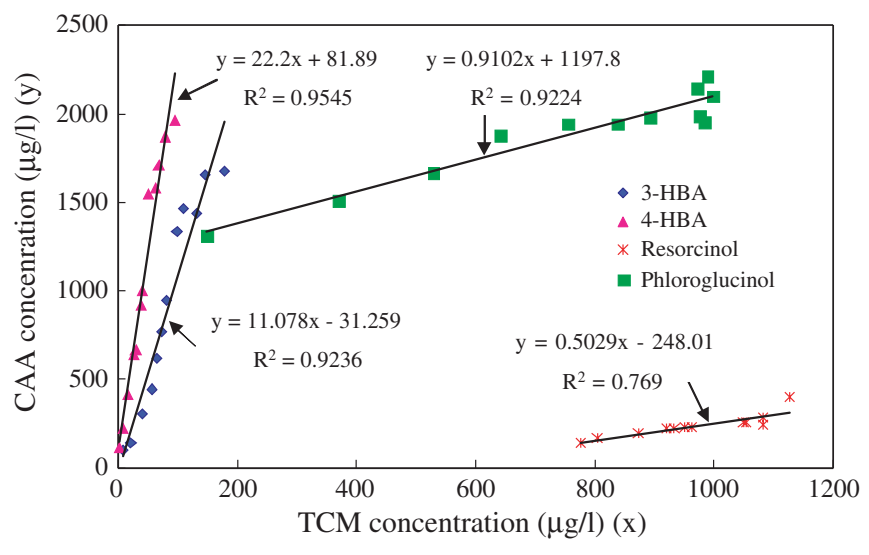

Fig. 7. Correlations between TCM and CAA concentration for model compounds.

strate ratios enhance the accumulation of chlorinated byproducts including TCM and CAA. The rate of $\mathrm{CHCl}_{3}$ production and chlorine consumption varied with each model compound, however, the overall data showed two distinct patterns. The first pattern exhibited by the hydroxybenzene reflects a generally rapid and simultaneous exertion of both chlorine demand and TCM production. The second pattern demonstrated by the hydroxybenzoic acids indicates that TCM is a minor reaction product. Further, the $\mathrm{COOH}$ substitution substances existed in the 3 -HBA and 4-HBA compounds have lower $\mathrm{p} K_{\mathrm{a}}$ values produced more CAAFP. CAA formation of model compounds shows a high correlation with TCM formation.

The parallel second and first-order reaction model for chlorine demand derived in this study is the best fit which can be utilized for TCM, CAA and DBP formation modeling. The parallel third order (rapid reaction) and first order (slow reaction) exhibits the highest correlation coefficient (best fit) for the four model compounds with the exception of $\mathrm{P}$ for CAA model prediction.

From this study, it may be concluded that the distribution of various species of chlorinated products depends on the acidity $\left(\mathrm{p} K_{\mathrm{a}}\right), \mathrm{SUVA}_{254}$ and characteristics of the substrate in the solution. The formation of DBP is highly dependent upon the nature of the organic matter. Although these four small model compounds have their respective functional group reacted with chlorine to form DBP, the developed model in this investigation can be successful in predicting the DBP formation. 


\section{Acknowledgement}

The authors express their thanks to the National Science Council, Taiwan, ROC (NSC 92-2211-E-038-001-) for its financial support of this study.

\section{References}

APHA, 1998. Standard Methods for the Examination of Water and Wastewater, 20th ed. American Public Health Association, Washington, DC.

Amy, G.L., Chadik, P.A., Chowdhury, Z.K., 1987. Developing models for predicting trihalomethane formation potential and kinetics. J. AWWA 79 (7), 89-97.

Boyce, S.D., Hornig, J.F., 1983. Reaction pathways of trihalomethane formation from the halogenation of dihydroxyaromatic model compounds for humic acid. Environ. Sci. Technol. 17 (4), 202-211.

Chang, E.E., Chiang, P.C., Chao, S.H., Lee, J.F., 1996. Effects of chlorination on THMs formation in raw water. J. Toxicol. Environ. Chem. 56, 211-215.

Chang, E.E., Chaing, P.C., Ko, Y.W., Lan, W.S., 2001. Characteristics of organic precursors and their relationship with disinfection by-products. Chemosphere 44 (5), 1231-1236.

Chiang, P.C., Chang, E.E., Liang, C.H., 2002. NOM characteristics and treatabilities of ozonation processes. Chemosphere 46 (4), 929-936.

Christman, R.F., Johnson, J.D., Haas, J.R., Pfaender, F.K., Liao, W.T., Norwood, D.L., Alexander, H.J., 1978. Natural and model aquatic humics: reactions with chlorine. In: Robert, L.J. et al. (Eds.), Water Chlorination: Environmental Impacts and Health Effects, vol. 2. Ann Arbor Science Publishers, Inc., Ann Arbor, MI.

Cook, R., Langford, C.H., 1998. Structural characterization of fulvic acid and humic acid using solid-state ramp-CP-MAS 13C nuclear magnetic resonance. Environ. Sci. Technol. 32 (6), 719-725.

Dotson, D., Helz, G.R., 1984Water Chlorination: Chemistry Environmental Impact and Health Effects, vol. 5. Lewis Publishers.

Engerholm, B.A., Amy, G.L., 1983. A predictive model for chloroform formation from humic acid. J. AWWA 75 (8), 418-423.

Gallard, H., Gunten, U.V., 2002. Chlorination of natural organic matter: kinetics of chlorination and of THM formation. Water Res. 36 (1), 65 74.
Gang, D.D., Segar, J.R., Clevenger, T.E., Banerji, S.K., 2002. Using chlorine demand to predict TTHM and HAA9 formation. J. AWWA 94 (10), 76-86.

Gang, D., Clevenger, T.E., Banerji, S.K., 2003. Relationship of chlorine decay and THMs formation to NOM size. J. Hazard. Mater. A 96 (1), $1-12$.

Katz, E.L., 1986. The stability of turbidity in raw water and its relationship to chlorine demand. J. AWWA 78 (2), 72-75.

Korshin, G.V., Li, C.W., Benjamin, M.M., 1997. Monitoring the properties of natural organic matter through UV spectroscopy: a consistent theory. Water Res. 31 (7), 1787.

Larson, R.A., Rockwell, A.L., 1979. Chloroform and chlorophenol production by decarboxylation of natural acids during aqueous chlorination. Environ. Sci. Technol. 13 (3), 325-329.

Liang, L., Singer, P.C., 2001. Factors influencing the formation and relative distribution of haloacetic acids and trihalomethane under controlled chlorination conditions, in: Proceedings of the American Water Works Association and Water Quality Technology Conference, Tennessee, 11-15 November 2001.

Marhaba, T.F., Van, D., 2000. The variation of mass and disinfection by product formation potential of dissolved organic matter fractions along a conventional surface water treatment plant. J. Hazard Mater. 74 (3), 133-147.

Norwood, D.L., Johnson, J.D., Christman, R.F., Hass, J.R., Bobenrieth, M.R., 1980. Reactions of chlorine with selected aromatic models of aquatic humic material. Environ. Sci. Technol. 14 (2), 187-190.

Peters, C.J., Young, R.J., Perry, R., 1980. Factors influencing the formation of haloforms in the chlorination of humic substances. Environ. Sci. Technol. 14 (11), 1391-1395.

Pomes, M.L., Green, W.R., Thurman, E.M., Orem, W.H., Lerch, H.E., 1999. DBP formation of aquatic humic substances. J. AWWA 91 (3), $103-115$.

Reckhow, D.A., Singer, P.C., Malcolm, R.L., 1990. Chlorination of humic materials: byproduct formation and chemical interpretations. Envrion. Sci. Technol. 24 (11), 1655-1664.

Rook, J.J., 1976. Haloforms in drinking water. J. AWWA 68 (3), 168172.

Trussell, R.R., Umphres, M.D., 1978. The formation of trihalomethanes. J. AWWA 11, 604-612.

Sinha, S., 1999. Coagulability of NOM and its effects on formation of chlorination DBPs, Ph.D. dissertation, University of Colorado at Boulder, Colorado, 1999. 